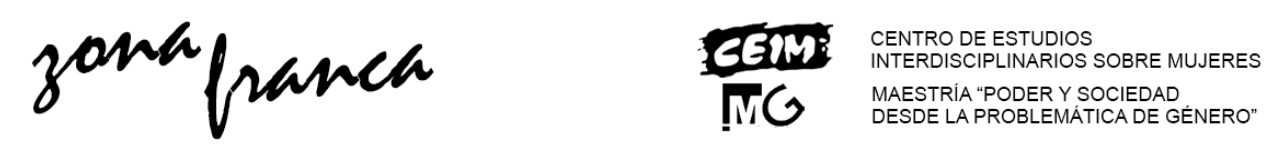

\title{
Cartografías subjetivas en las novelas La mujer desnuda (1950) y Viaje al corazón del día (1986) de Armonía Somers (1914-1994)
}

Ulla Szaszak Bongartz*

\section{Resumen}

En este artículo propongo explorar la construcción de subjetividades literarias en la primera y la penúltima novela de la escritora uruguaya Armonía Somers (19141994), a partir del trazado de cartografías subjetivas que articulen el lenguaje visual y el lingüístico. El objetivo es considerar cómo las "subjetividades delirantes" (Guattari, 1986) que fabrica Somers portan un potencial de minar la subjetividad dominante en cada uno de los universos narrativos; $y$, por otra parte, ponderar en qué medida la plasticidad de los personajes elabora un mapa identitario móvil. Dado que los personajes ensayan

nuevos posicionamientos en relación al género, al deseo, a la moral y a la religión, es posible reparar en cómo -partiendo de la idea de Judith Butler de "replantear lo posible en cuanto tal" (1990 [2007: 24])-, se habilitan nuevas formas de identidad posible que escapan -al menos, de forma momentánea- a las mallas represivas del poder ${ }^{* *}$.

Palabras clave: subjetividad, identidad, cartografía subjetiva, literatura, género

* Universidad de Buenos Aires- Universidad Nacional de Tres de Febrero. Contacto: ullaszaszak@gmail.com

** Este artículo deriva de un capítulo de mi tesis de maestría, perteneciente al programa de Estudios Literarios Latinoamericanos de la UNTREF, denominada Subjetividades y nombres propios en las novelas de Armonía Somers: una poética de la suplementariedad nominal.

Szaszak Bongartz, Ulla. "Cartografías subjetivas en las novelas La mujer desnuda (1950) y Viaje al corazón del día (1986) de Armonía Somers (1914-1994)" en Zona Franca. Revista del Centro de estudios Interdisciplinario sobre las Mujeres, y de la Maestría poder y sociedad desde la problemática de Género, №28, 2020 pp. 412-435. ISSN, 2545-6504 Recibido: 9 de mayo 2020; Aceptado: 29 de setiembre 2020

Revista Zona Franca- Centro de estudios interdisciplinario sobre las mujeres (CEIM)- Maestría poder y sociedad desde la problemática de género (MG), Rosario, Argentina. ISSN, 2545-6504 http://zonafranca.unr.edu.ar/index.php/ZonaFrancal Número 28 (2020). 


\title{
Mapping of subjectivities in the novels La mujer desnuda (1950) and Viaje al corazón del día (1986) by Armonía Somers (1914-1994)
}

\begin{abstract}
In this article, I intend to explore the construction of literary subjectivities in the first and the penultimate novel by Uruguayan writer Armonía Somers (1914-1994), based on the mapping of subjectivities that articulates the visual and linguistic language. The objective is to ponder how the "delusional subjectivities" (Guattari, 1986) that Somers manufactures have a potential to undermine the dominant subjectivity of each of the narrative universes. Furthermore, we aim to consider to what extent the plasticity of the characters elaborates a mobile identity map. Because the characters transform themselves into new positions in relation to gender, desire, morality and religion, it is possible to consider how -based on the idea of Judith Butler of "rethinking what is possible as such" (1990 [2007: 24])-, new forms of identity are enabled which escape (at least momentarily) the repressive forms of power.
\end{abstract}

Keywords: subjectivity, identity, literature, gender, mapping of subjectivities

\section{Introducción}

Si un mapa produce sentido en la articulación de, por lo menos, dos lenguajes: el visual y el lingüístico, -hecho que favorece un tipo de pensamiento plástico-; podríamos señalar que una cartografía subjetiva es un ensayo experimental, que tiende a reconstruir ( $y$ construir) las formas de interrelación y de agenciamientos ( $u$ oposiciones) entre sujetos (en este caso, de personajes literarios). Según Deleuze y Guattari un mapa no reproduce un inconsciente cerrado sobre sí mismo, sino que lo construye, al tiempo que habilita la conexión de los campos, el desbloqueo de los cuerpos sin órganos y la apertura; además, es desmontable y conectable en todas sus dimensiones.

En este sentido, desde el horizonte teórico contemporáneo que atiende con ojos ávidos a la proliferación y descentramiento de la(s) subjetividad(es) y la(s)

Revista Zona Franca- Centro de estudios interdisciplinario sobre las mujeres (CEIM)- Maestría poder y sociedad desde la problemática de género (MG), Rosario, Argentina. ISSN, 2545-6504 http://zonafranca.unr.edu.ar/index.php/ZonaFrancal Número 28 (2020). 
identidad(es) en el plano sociológico y tecnológico -que se intensifican desde alrededor de los años '80-, este artículo propone leer, con el auxilio de dicho aparato crítico y otros (y a riesgo de incurrir en un aparente anacronismo), dos novelas de una escritora desplazada e invisibilizada en el canon literario latinoamericano del siglo XX, y luego convertida en autora de culto: Armonía Somers (1914-1994). Del mismo modo que en otras de sus novelas (como Un retrato para Dickens o Sólo los elefantes encuentran mandrágora) las nouvelles que consideraremos -la primera: La mujer desnuda (1950 [2009]) y la anteúltima: Viaje al corazón del día: elegía por un secreto amor (1986 [2011])-, se caracterizan, en gran medida, por la fabricación de "subjetividades delirantes" (Félix Guattari): cualquier atisbo de una subjetividad "dominante" queda inmediatamente minada por la productividad identitaria que sus personajes presentan. En este sentido, la novelística somersiana produce personajes elásticos de forma incansable, insertos en un mapa o cartografía de subjetividades que se reorganiza, transforma y deviene, al tiempo que los personajes se modifican a sí mismos, en una modulación constante.

Si bien la fluencia que postulan Deleuze y Guattari en relación a los mapas está ligada con el axioma rizomático de la producción de líneas -y no de puntos o posiciones-, consideramos, no obstante, importante cartografiar las posiciones subjetivas que los personajes de Somers adoptan transitoriamente, dentro de los diagramas móviles y en devenir. Es posible, de este modo, tomar una suerte de "fotografía instantánea" de las formas de relación que se desprenden de ellas, pero no para fijar y estabilizar dichas posiciones (o lo que parecería un sinónimo, neutralizarlas), sino para dar cuenta de las líneas de fuerzas, de las oposiciones, de las formas subjetivas diferenciales y en pugna que permean efectivamente la producción estética, crítica -social en general-, y cuya extirpación total no nos parece ni primordial ni posible. Más bien, nos resulta fructífera una amalgama que construya un dispositivo de lectura híbrido.

Por ende, recurrimos a otra parte del espectro teórico: dentro de los Estudios Culturales, a la perspectiva de Stuart Hall. Este autor concibe el concepto de

Revista Zona Franca- Centro de estudios interdisciplinario sobre las mujeres (CEIM)- Maestría poder y sociedad desde la problemática de género (MG), Rosario, Argentina. ISSN, 2545-6504 http://zonafranca.unr.edu.ar/index.php/ZonaFranca| Número 28 (2020). 
identidad como fundado sobre un "juego de la diferencia" que no es fijo y está en constante desestabilización, por lo cual se presenta como estratégico y posicional. Asimismo, ésta se funda sobre prácticas discursivas -siguiendo a Michel Foucaultque construyen puntos de adhesión temporales con la que los sujetos se identifican. En efecto, lo que se intuye detrás de estos modos de relación es la existencia de un entramado "global" -inestable y dinámico- de subjetividades particulares que adoptan ciertas posiciones de forma circunstancial. Consideramos importante este mapeo en el marco de una "globalidad" abstracta y abierta a variación porque permite aprehender dónde se producen "los procesos de singularización" de los personajes que rechazan la máquina de subjetividad fabricada, serializada y consumida en el registro de lo social, en términos de Félix Guattari.

De este modo, nos proponemos trazar diagramas narrativo-identitarios dentro de estas dos novelas consignadas. El recorrido que las une es una suerte de arco: en La mujer desnuda (1950) las figuras que le sirven a la protagonista en su autofiguración subjetiva remiten a un universo de referencias culturales, simbólicas y míticas en gran medida abstractas. Cerca del final de la producción novelística de Somers, ya en Viaje al corazón del día: elegía por un secreto amor, el universo cultural que sirve a los personajes de fuente de ensayo para sus re-subjetivaciones adquiere mayor particularidad, y la apropiación que éstos hacen de él es más íntima, anclada y concreta.

\section{Mapeo de subjetividades en La mujer desnuda Entre identidades}

\section{marcadas y desmarcadas}

Con el objeto de pensar las transformaciones subjetivas que se efectúan en la primera nouvelle, La mujer desnuda (en adelante: $L M D^{\prime}$ ), publicada en Montevideo

\footnotetext{
' La mujer desnuda es la primera novela de Armonía Liropeya Etchepare Locino publicada con el seudónimo Armonía Somers. Su marco de aparición es una sociedad uruguaya paternalista, conservadora, hipócrita, donde el tema sexual se elude con pudor (Franco 84). De hecho, la "generación de los alacranes" del '45 la recibió en un primer momento con reticencia; y se le endosó, además de defectos estructurales y estilísticos, el contar con una "obsesión erótica" (Rodríguez
}

Revista Zona Franca- Centro de estudios interdisciplinario sobre las mujeres (CEIM)- Maestría poder y sociedad desde la problemática de género (MG), Rosario, Argentina. ISSN, 2545-6504 http://zonafranca.unr.edu.ar/index.php/ZonaFranca| Número 28 (2020). 
en 1950, debemos hacer un breve recorrido por la trama. El día de su cumpleaños número treinta -que llega "sin marca visible" y confirma el inicio de la "nada" (Somers 1950 16)- Rebeca Linke, la protagonista, viaja a medianoche desde la ciudad hacia una casa que compró en el campo, vestida únicamente con un tapado. Al llegar, dispuesta a "vivir su acontecimiento propio" (1950 16), se decapita por mano propia, nombra su cabeza como "Amanda", vuelve a colocársela y sale, ahora desnuda, a vagar por el bosque. Al "entrever" el sueño de un leñador, ingresa sin permiso en su casa mientras él y su mujer duermen. Se acuesta a su lado, le habla en sueños y le toca el pecho, incitándolo a que él también la toque y cuando el hombre pregunta su nombre, responde que sus nombres son: "Eva", "Judith", "Semíramis", "Magdala" y también "Gradiva". Temiendo ser reducida por el hombre a un régimen nupcial basado en la posesión, la transacción de bienes y el acato a una moral, se escabulle y continúa su trayecto por el campo. Dos gemelos del pueblo, al verla, hacen correr la voz y empieza a crecer una fantasmagoría colectiva respecto a esta "mujer desnuda". Emerge una violencia sexual y patriarcal: los maridos aldeanos violan a sus resignadas mujeres, les exigen cosas. En ese marco, se hace una misa en que el cura, alucinado ( $y$ en contra del hábito aldeano) exculpa a la mujer por su desnudez; pero sin embargo, todo el pueblo sale con sus armas para buscarla. Cuando la protagonista llega a la casa de Juan, un lugareño, ella se presenta como Friné y ambos se enamoran. Finalmente los aldeanos los encuentran, golpean a Juan hasta que queda agonizante, y Friné sigue caminando hasta el río. Un caballo logra cruzarlo por encima de las aguas, pero cuando ella lo intenta, se hunde en remolinos y termina por ahogarse.

En primer lugar, la alteración subjetiva de Rebeca Linke, que empieza a ocurrir desde el principio del relato, está motivada por los atributos que confirman su

Monegal, 1953), a raíz de El derrumbamiento. No es menor que esta obra se tense de forma tan directa respecto a su contexto de producción y recepción; y se vuelva exhibicionista de problemas que atañen a la moral, al erotismo y a los sujetos, en el plano temático. También, se verifican en ella cuestiones de "fantasticidad sintáctica" (Rodríguez Villamil, 1990): formas constructivas surrealistas, e incluso expresionistas, cuya identificación, y consiguiente novedad respecto de lecturas previas, es rastreada por Ángel Rama en un artículo de 1966.

Revista Zona Franca- Centro de estudios interdisciplinario sobre las mujeres (CEIM)- Maestría poder y sociedad desde la problemática de género (MG), Rosario, Argentina. ISSN, 2545-6504 http://zonafranca.unr.edu.ar/index.php/ZonaFranca| Número 28 (2020). 
cumpleaños de treinta: lo que adviene "sin marca", sin cualidad memorable y se constituye como "la nada". Estos rasgos, aplicados a una exterioridad pero que al mismo tiempo son introyectados -se produce una identificación o un plegamiento sobre éstos por parte de la protagonista-, parecen gravitar en torno a lo neutro: aquel "calificativo sin calidad", según Maurice Blanchot, que está "elevado al rango de sustantivo sin subsistencia ni sustancia" (1993 477). Si la "extrañeza", para Blanchot, es cercana a "lo neutro", porque indica "la disolución misma de la identidad, donde no hay nada más que alteración" (Blanchot 2001 85)"; se puede pensar aquella otredad como la que se entromete en lo idéntico a sí mismo -la mismidad en Ricoeur (2006)-, y lo trastoca. De este modo, la otredad no se constituye en oposición a una identidad, sino que es una dispersión al infinito de ésta última (Potente). Lo neutro, junto con lo Otro, sería lo que no cae bajo la jurisdicción de lo Uno (Blanchot 1993 485). En ese sentido, las subjetividades literarias que tienden a lo neutro, o a lo que se neutraliza, parecerían -como trataremos de probar- más permeables a la otredad y a las alteraciones internas que entraña el juego intersubjetivo, y por tanto, a proliferar subjetivamente.

Estos rasgos de ausencia de cualificación aparecen reforzados con la llegada de Rebeca Linke a la finca. Ésta parece estar "suspendida en la atmósfera" (Somers, 195015$]$ ), y configura un espacio extraño porque ella apenas conoce sus interiores. Se encuentra, entonces, "completamente despojada de todo vínculo anterior y casi con la sensación de un regreso a la matriz primitiva" (1950 [2009: 17]) $y$, sin embargo, lista para vivir su "acontecimiento propio" "II. De modo que esta cualidad de Rebeca Linke de estar desmarcada, desprovista de huellas, de memoria (propia y ajena) y en las puertas de la nada, marca no solo una suerte de desubjetivación en que el "yo" parece proyectarse a un puro presente, sino que implica la ruptura de los vínculos previos, una a-socialización y una vuelta a la citada "matriz primitiva", como forma de desterritorialización (Deleuze y Guattari, 1980

\footnotetext{
"Los subrayados son propios.

III Los subrayados son propios.
}

Revista Zona Franca- Centro de estudios interdisciplinario sobre las mujeres (CEIM)- Maestría poder y sociedad desde la problemática de género (MG), Rosario, Argentina. ISSN, 2545-6504 http://zonafranca.unr.edu.ar/index.php/ZonaFranca| Número 28 (2020). 
[2002]). En ese punto, Ana María Rodríguez Villamil describe la figura del útero materno como una "vuelta a un estadio casi prenatal de la conciencia, donde los límites entre el yo y el tú o entre sujeto y objeto, no están claramente establecidos" (1990: 37) $)^{\mathrm{IV}}$, y por otra parte, la mención en el mismo sintagma de lo "primitivo" puede dar cuenta de una forma muy antigua y rudimentaria o, incluso, previa a la constitución de la cultura.

Todo este movimiento de deslocalización y de ida hacia lo neutro plantea una sucesión de regresiones para el personaje: una de tipo biológico-temporal figurada (de la adultez hacia el estadio embrionario); una cultural (de la "civilización" hacia lo "primitivo") y una psíquica, advertida por Rodríguez Villamil, que es un retroceso hacia las profundidades del inconsciente -colectivo, como deberíamos agregar, en función del uso del plano simbólico-. Esta regresión psíquica toma como punto de partida al personaje en su condición de individuo, como lo piensa Guattari (2006), en tanto terminal individual en posición de consumidor de subjetividad, pero en el preciso momento en que se despoja de su carácter serializado, registrado y modelado. Esto es, Rebeca Linke introduce, como veremos, procesos de singularización en el seno de los agenciamientos colectivos de subjetivación que adoptan la forma, paradójica, de una regresión a aquellos arquetipos religiosos o míticos, que pertenecen al mundo simbólico, desrealizado (la "Eva”, “Judith" y María Magdalena ("Magdala") bíblicas, la "Semíramis" asiria y la "Gradiva" de la literatura), $y$, al mismo tiempo, tienen implicancias de desubjetivación en la protagonista. Es decir, se trataría de una singularización que se opera -quizás contradictoriamente, a partir de su fusión con figuras míticas, culturales y por tanto, colectivas, como veremos. De este modo, lo que parece originarse en la vuelta embrionaria es la idea de un renacimiento abstracto y desubjetivado, en que se abandona el yo

\footnotetext{
Iv Aunque Rodríguez Villamil use aquel tópico clásico del fantástico según Tzvetan Todorov, aquella forma de intermediación entre el yo y el tú, o entre sujeto y objeto; se puede pensar también aquel mismo fenómeno (para no caer en una rigidez genérica que describe muy bien, pero al mismo tiempo, obtura) en términos de lo neutro blanchotiano, o de proliferaciones subjetivas que al mismo tiempo habilitan nuevos y diversos agenciamientos subjetivos.
}

Revista Zona Franca- Centro de estudios interdisciplinario sobre las mujeres (CEIM)- Maestría poder y sociedad desde la problemática de género (MG), Rosario, Argentina. ISSN, 2545-6504 http://zonafranca.unr.edu.ar/index.php/ZonaFrancal Número 28 (2020). Página 418 
personal, la memoria y los vínculos que lo constituyen y se dispone a habitar otros "yoes", invocando dichas figuras transversales de la religión, el mito y la literatura.

Un primer punto de acceso a la ecología subjetiva del texto es -en virtud de este análisis preliminar- es la relación de oposición o de contrapunto entre Rebeca Linke (que por otra parte, pierde su nombre para ganar otros) ${ }^{\vee}$ y las otras mujeres aldeanas. Por un lado, se verifica el carácter desmarcado de la identificación subjetiva más reciente de Rebeca Linke: "Treinta años. Dejó su vida personal atrás, sobre una rara frontera sin memoria" (1950 24). A esto se suma su carácter nómade adquirido. En contraposición, Antonia, una aldeana y esposa del leñador "es como la marca de un cuadro en la pared, cuando ya nadie puede recordar cómo diablos sería el retrato (...) pero no hablará, por suerte no acostumbra, supe quebrarla a tiempo hace ya muchos años" (1950 36) (Los subrayados son míos). De modo que la posibilidad de la protagonista de deshacerse de la marca (o de la rectificación de su inexistencia), con el despojo de sus vínculos previos, de su memoria, de fragmentos de anatomía (la cabeza que vuelve, aunque distinta, a ocupar su lugar) y de su ropa como "antigua piel", la inviste de una intensa, peligrosa y corta libertad.

Por el contrario, la definición de la mujer aldeana como "una marca" refiere no sólo a aquella subjetividad apresada y afincada en la moral (aldeana-cristiana), en un espacio: (la "pared" en la metáfora, la "casa" en su traslación narrativa, acorde a la institución patriarcal) y su correlato: un rol impuesto (madre, esposa). Además, está sujeta al borroneo y al desvanecimiento de su imagen en el cuadro. No es un sujeto "neutro", sino más bien desvalido y expoliado: su desdibujamiento es una metáfora de su a-sexualización y de sometimiento al esquema moral-patriarcal que rige en la aldea, pero también indica el empequeñecimiento subjetivo, una decoloración identitaria. Se trata de un indicador del triunfo del patriarca modesto y empobrecido, de haberla podido "quebrar" como sujeto. De hecho, luego de su

\footnotetext{
${ }^{\vee}$ La cuestión del nombre propio se encuentra más extensamente trabajada en mi tesis de la maestría de Estudios Literarios Latinoamericanos, denominada "Subjetividad(es) y nombres propios en las novelas de Armonía Somers: una poética de la suplementariedad nominal".
}

Revista Zona Franca- Centro de estudios interdisciplinario sobre las mujeres (CEIM)- Maestría poder y sociedad desde la problemática de género (MG), Rosario, Argentina. ISSN, 2545-6504 http://zonafranca.unr.edu.ar/index.php/ZonaFranca| Número 28 (2020). Página 419 
breve contacto con Rebeca-Eva-Semíramis-Magdala, Gradiva, Nataniel viola brutalmente a su esposa Antonia: hendiéndola "a golpes de sexo como si esgrimiese el hacha contra un árbol" (1950 29). La "niña-vieja", como se la nombra -lo cual hace pensar en una persona que se "saltea" el momento de ser mujer, como resultado de su reducción y aplastamiento patriarcal y su dependencia impuesta-, lo único que puede hacer es resignarse de forma pasiva, y proceder con sus tareas de cuidado. Después de que el marido acaba de violarla, ella le prepara un té de tilo.

La distribución de subjetividades que se opera en el esquema narrativo se produce en términos abstractos entre el yo "desmarcado", "desmemoriado", desnudo, mudable de la protagonista, ostensible en los sucesivos suplementos nominales adoptados por Rebeca Linke; y los yoes aldeanos en general, "marcados", estáticos y anclados en la costumbre. De modo que se trata de la diferencia entre la neutralidad (Rebeca Linke) y la cualificación (los aldeanos); entre el movimiento de la protagonista y la fijeza de los habitantes del pueblo. Hay dos aldeanos que escapan a la rigidización: el cura y Juan. El primero muere inmolado y el otro, sacrificado por los habitantes del pueblo. Esto es, aquellos que flexibilizan y reversionan el dogma religioso, en el caso del cura, quien exime de culpabilidades a la Eva original y a su réplica terrena: "sois vosotros, pues, los suciamente desnudos y no ella" (1950 75). Éste es el primer momento en que se nombra la presencia de la mujer desnuda en relación al mito del génesis: en el ámbito colectivo del sermón. Juan, por su parte, es el único que tiene un vínculo sexual y amoroso con ella, y que no la objetualiza ni la censura. El resto de los aldeanos, por el contrario, sienten la emergencia de los deseos sexuales reprimidos, y culpabilizan a la mujer desnuda y a sí mismos; como gozan y desean con culpa, ella los "golpea en su impotencia" y por eso su existencia es intolerable.

\section{El nomadismo y la desnudez como formas de habitar}

Revista Zona Franca- Centro de estudios interdisciplinario sobre las mujeres (CEIM)- Maestría poder y sociedad desde la problemática de género (MG), Rosario, Argentina. ISSN, 2545-6504 http://zonafranca.unr.edu.ar/index.php/ZonaFranca| Número 28 (2020).

Página 420 
Hay dos características de Rebeca Linke que se desprenden de su condición de estar desmarcada y libre de sujeciones: una es su consecuencia directa $-\mathrm{y}$ posiblemente, la primera cualidad, que en tanto tal se sustrae de la neutralidad-, que es la del movimiento, o la del nomadismo subjetivo (Braidotti); la otra, contrasta y radicaliza la imposibilidad de aquella utopía de la desregulación subjetiva y el carácter desmarcado, y expone la existencia de "la marca" como algo radical e inalienable, esto es, la marca sexual (y luego, genérica), es decir, su materialismo subjetivo 0 incardinamiento en términos de Rosi Braidotti. El primer rasgo del nomadismo subjetivo es que la condición vital primaria de la protagonista sea la errancia. Esto es porque todo el devenir narrativo está signado -y condicionadopor la idea de trayectos. El primero de éstos es maquínico: el acto de viajar en tren de la ciudad al campo; y el segundo, biomecánico: caminar a lo largo de tres días por el bosque y la pradera.

Rosi Braidotti señala que una subjetividad nómade propone una forma "intransitiva de devenir" y por tanto, no teleológica; y además constituye una "cartografía viviente del presente" que "crea mapas políticamente informados de su propia supervivencia" (182) (El subrayado es propio). Si bien en la idea del "presente" Braidotti se refiere a una marca temporal, la idea de una contemporaneidad al contexto de producción del ensayo; hay -salvando las distancias- una especie de recuperación del presente entendido como categoría temporal genérica. El nomadismo de la mujer desnuda inaugura un modo vivencial de perpetuo presente, en que no hay ligazón con los otros tiempos, sino un efecto de actualización, renovación a-causal o relampagueo de instantaneidad. Cuando la protagonista se encuentra con el caballo en el campo, por ejemplo, el narrador explica: "el animal se transformó de golpe en la síntesis de todo lo existente. Nunca hasta entonces había sentido y mirado uno tan de cerca." (Somers, 1950 39). En este sentido, podemos señalar que el trayecto que se impone dibuja un mapa político-moral y de género que rastrea la supervivencia de Rebeca-Eva-SemíramisMagdala, Gradiva, hasta su muerte. Sin embargo, su recorrido no se detiene: sigue

Revista Zona Franca- Centro de estudios interdisciplinario sobre las mujeres (CEIM)- Maestría poder y sociedad desde la problemática de género (MG), Rosario, Argentina. ISSN, 2545-6504 http://zonafranca.unr.edu.ar/index.php/ZonaFranca| Número 28 (2020). 
itinerante en su condición de cadáver por el río. En términos de los alcances que tiene el nomadismo de la protagonista, éste no sólo produce alteraciones subjetivas y nominales en el personaje (sujeto a una ipseidad radical (Ricoeur), sino también un efecto de onda expansiva, que se extiende hacia la colectividad y hace brotar la sexualidad reprimida y, asimismo, la violencia patriarcal. No obstante, en otro registro produce también sentimientos amorosos (en Juan) y de impugnación de la moral religiosa (en el cura). Su vagar implica una amenaza: lo primero que ven los gemelos cuando la avistan en el campo es que "aquello" se mueve "como si desplazara las raíces" (Somers, 1950 38). El marco de referencia es el reino vegetal, que es lo que habita esos espacios (y no personas), y en el "desplazamiento de raíces" se cifra una idea de algo contrario a la naturaleza, y por tanto, monstruoso. Otro efecto de dicha errancia anónima, alejada de la ciudad y la vigilancia de la ley, es que se produce una abolición de las fronteras entre espacios personales o privados y los espacios comunes o públicos: la protagonista viola la propiedad privada del leñador cuando entra sin permiso y se acuesta a su lado. Lo interesante es, precisamente, la posibilidad de traslado irrestricto de un espacio al otro. Éstos, a su vez, más allá de su estatuto, son zonas desconocidas y ajenas para la protagonista, y es la cualidad nómade la que permite ensayar modos de atravesarlos, e incluso de transgredirlos. A pesar de esto, su presencia en los lugares comunes es igual de perturbadora y, desde el punto de vista de los lugareños, debe ser rectificada.

A pesar del carácter primordialmente desmarcado de la protagonista hay, sin embargo, un factor de anclaje irreductible y, por lo tanto, de "marca", en la protagonista, lo cual redunda en la fatalidad de la que no está exenta. Y este es su efectivo "materialismo" subjetivo, su incardinamiento; frente a aquello que podría parecer libre e irrestricto. De modo que la deslocalización de Rebeca Linke-EvaJudith-Semíramis-Gradiva-Magdala-Friné, su acción de deambular por los alrededores agrestes de la aldea en los que es una extraña no implica, en absoluto, el efecto de un cuerpo desmaterializado. De hecho, la "marca" del sexo femenino

Revista Zona Franca- Centro de estudios interdisciplinario sobre las mujeres (CEIM)- Maestría poder y sociedad desde la problemática de género (MG), Rosario, Argentina. ISSN, 2545-6504 http://zonafranca.unr.edu.ar/index.php/ZonaFrancal Número 28 (2020). 
en su exhibición radical (y su plegamiento a la construcción genérica de la femineidad) se presenta en su calidad de "irreductible exceso" -cuya pérdida temía Gisela Catanzaro en favor del concepto y la unidad de las identidades (posmodernas)-. El cuerpo textual de la mujer desnuda es un "resto inasimilable del sistema" que por su exposición, su existencia radical, no se puede domesticar desde el concepto. Se presenta como insoportable y disruptivo y es por eso que se inicia una cacería para someterla. Los devenires subjetivos de la protagonista están en parte asentados por aquellas dos nuevas formas de habitar el mundo: la desnudez y el tránsito.

Si la materialidad corporal y el incardinamiento implican una localización primaria en el mundo; y en el cuerpo se superponen lo físico, lo simbólico y lo sociológico; entonces el cuerpo es también aquel en que se inscribe la experiencia de forma tangible, como trazos físicos. Como resultado de esta nueva vida nómade a la intemperie:

No dejaba entonces de ser importante que (...) sólo doliesen los pies que andan, el pelo que se engancha, el estómago con su maldita hambre congénita. Cavan mucho más hondo las garras del humor, las ligaduras y los círculos que uno se fabrica con sus propios dedos, y luego se entretiene en ajustar hasta el último minuto (1950 87).

Se trata de un sujeto en que también las necesidades corporales y las lastimaduras infligidas por una naturaleza hostil producen una subjetivación particular: un cuerpo visible, frágil y apresable. Juan la define como "una mujer herida". Ella gana y pierde partes de sí en la naturaleza; reformula su subjetividad en las alteraciones corporales que allí ocurren: "se liberó dejando algunos pedazos de sí en las ramas, llevándose otros ajenos consigo, y siguió avanzando" (1950 86). Además, no tiene "la mentida blandura" que sugiere a la distancia, es más bien "áspera" (86). De modo que la fatalidad subjetiva ocurre en el umbral de un cuerpo sexuado, de mujer, aquejado por dolencias y afectos, su flanco vulnerable.

Revista Zona Franca- Centro de estudios interdisciplinario sobre las mujeres (CEIM)- Maestría poder y sociedad desde la problemática de género (MG), Rosario, Argentina. ISSN, 2545-6504 http://zonafranca.unr.edu.ar/index.php/ZonaFranca| Número 28 (2020). 
Además de la estructura de relaciones entre subjetividades marcadas y desmarcadas, también podemos apelar a las nociones de la indiferencia (no sólo en términos de ausencia de inclinación emocional hacia algo o alguien sino también de equivalencia o no diferenciación) y la del carácter diferencial, místico y "despierto", para dar cuenta de la distancia entre la protagonista y los habitantes de la aldea. Los pueblerinos son presentados como hombres y mujeres "comunes":

Aquellos brutos dormidos eran, en realidad, la expresión plástica de la indiferencia, quizás la misma que había quedado tras el bosque, los ferrocarriles, las calles con plazas y con tiendas que ella había dejado en la ciudad y que a puro olfato estaría segura de reconocer en cualquier parte (26) (El subrayado es mío).

El índice de distancia entre la mujer desnuda y los "brutos dormidos" es la misma que con los ferrocarriles, plazas y tiendas de la ciudad: la indiferencia no sólo aparece como apatía o desinterés sino también en relación a lo indiferenciado, a lo que no se discierne, a lo que es igual al resto, por ejemplo, ajustarse a los códigos y convenciones morales imperantes: la máquina de producción de subjetividad. En el caso de los habitantes del pueblo se trata de trabajar, profesar la fe; las mujeres de engendrar los hijos, cuidar del hogar, etc. ${ }^{\mathrm{VI}}$ En este sentido la mujer desnuda sería la que "despierta" a los otros de la adecuación a la norma moral y de la indiferenciación (incluso con sus consecuencias más nefastas: las violencias sexuales y asesinas) y vive de forma primitiva, invistiéndose simbólicamente de otras mujeres y sensible a la plasticidad intersubjetiva. Puede, por ejemplo, "entrever" desde el bosque, "el sueño simple de un hombre común" (24) a la distancia, antes de entrar en la casa de éste. Es decir que tiene acceso a los sueños y a la vigilia de los demás. Este retroceso al inconsciente, propio y colectivo, se apuntala desde el aspecto narrativo, a partir de indicios de desrealización y de una

${ }^{\mathrm{VI}}$ En el texto se explicita dicho carácter indiferenciado y reglado: "más allá de ello iba a ser preciso teorizar, reducir el estado personal a normas compartidas o rechazadas, pero siempre reglas a transferirse para el uso del término medio. Y empezaría de nuevo el falseamiento, la angustia por convencer, aquél estúpido juego doméstico de la pobre gente". (Somers, 1950 32).

Revista Zona Franca- Centro de estudios interdisciplinario sobre las mujeres (CEIM)- Maestría poder y sociedad desde la problemática de género (MG), Rosario, Argentina. ISSN, 2545-6504 http://zonafranca.unr.edu.ar/index.php/ZonaFrancal Número 28 (2020). 
conciencia alterada. Entre aquellos recursos está la confusión de tiempos verbales (y mentales) -pasado, presente y futuro- que conviven en una marea simultánea especialmente en la escena en que Rebeca Linke llega a la casa. Aquellos recuerdos, percepciones y expectativas mezclados parecen coquetear con aquel recurso propio del modernismo anglosajón: el flujo de consciencia o stream of

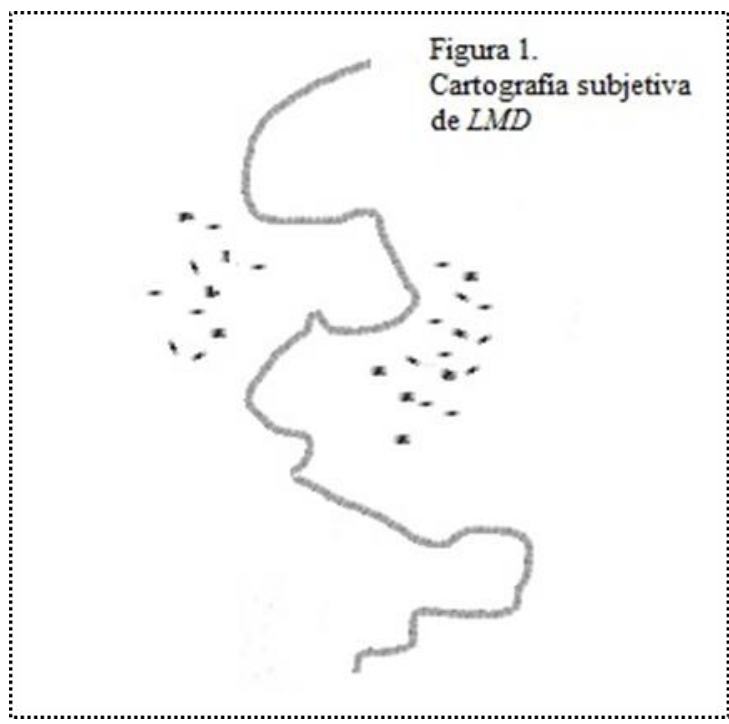
consciousness ${ }^{\mathrm{VII}}$. También, por supuesto, se produce un contacto con el programa estético del surrealismo -0 superrealismo-, que reproduce lo errático del pensamiento: la simultaneidad entre el viaje en tren, el empleado que le pide el boleto, la cama de la casa en la pradera en que está acostada y el efecto de barrotes lumínicos de la persiana sobre su piel, entre otros. De modo que dichos recursos narrativos colaboran con el

carácter místico y diferencial que tendría la protagonista para remover los cimientos estáticos de las subjetividades aldeanas.

De modo que, para dar cuenta del mapa de subjetividades en $L M D$ en términos gráficos, concluimos que éste se basa, a grandes rasgos, en una distribución entre unas identidades fijas, patriarcales y afincadas en la moral y otra del tipo móvil, nómade y desmarcada, que redunda -si pensamos en términos cartográficos- en el trayecto ininterrumpido de Rebeca Linke como una línea como sucesión continua de puntos trazados, no sólo en sentido espacial, sino también subjetivo: los puntos

VII El psicólogo norteamericano William James -hermano del famoso novelista Henry James- en su obra titulada Principles of Psychology (1890) afirma que en la mente no hay una representación concreta de la realidad, sino un conjunto de imágenes, pensamientos, y recuerdos acumulados que afloran en un momento determinado de forma continua, como el fluir de un río; propone, entonces, el término de "stream of consciousness" (o flujo de la conciencia) para denominar esta actividad mental. Ese mismo término es utilizado después para describir aquellas novelas modernistas que pretenden crear en el lector la ilusión de que entra en la mente del personaje y puede seguir su contenido y proceso psíquicos tal y como se supone están en su subconsciente. (Lázaro 474).

Revista Zona Franca- Centro de estudios interdisciplinario sobre las mujeres (CEIM)- Maestría poder y sociedad desde la problemática de género (MG), Rosario, Argentina. ISSN, 2545-6504 http://zonafranca.unr.edu.ar/index.php/ZonaFranca| Número 28 (2020). 
de adhesión subjetiva van renovándose a lo largo del recorrido. Además, dicha línea tiene reverberaciones o ecos sobre su campo de proximidad: sus congéneres aldeanos; y también puntos de encuentro o breves plegamientos (conceptuales o materiales-emocionales) con algunos de los otros personajes más plásticos -el caso del personaje de Juan y el del cura-. De modo que se producen tanto agenciamientos subjetivos deseantes -que sin duda son los más interesantes en términos de matices intersubjetivos- como contraposiciones, bajo la forma de un antagonismo mortal, con las identidades que se afincan en la máquina de producción de subjetividad propia de un tipo de sociedad tradicional, religiosa y patriarcal.

\section{Mapeos de subjetividades en Viaje al corazón del día: elegía por un}

\section{secreto amor}

Si bien el argumento de Viaje al corazón del día: elegía por un secreto amor tiene, como señala Somers, rasgos de "teleteatro" o melodrama, la escritura propiamente dicha se aleja de estos géneros mediante una expulsión del efectismo sentimental, formas de construcción surrealistas y expresionistas de algunas escenas, exposición de hechos que permanecen como tabúes culturales, como el incesto, y el desdoblamiento de la voz narrativa entre Laura, la protagonista, y Hildegaard. En esta novela, el mapa de subjetividades se construye a partir de una suerte de triángulo jerárquico (más parecido a una lógica piramidal, que no deberíamos confundir con algunas lógicas triangulares no jerárquicas que aparecerán como alternativas deseantes), que tiene a Encarnación, tía de la protagonista, como cabeza del matriarcado (vértice superior), y que, en sus líneas diagonales, encarna un desplazamiento parental de los descendientes: una dislocación genealógica en términos de estructura familiar. Esto es porque está a cargo de su sobrina Laura, cuyos padres fallecieron en un naufragio; y también oficia de madre sustituta para su nieto (el hijo de su propia hija, Eulalia). De modo que Encarnación es una tía y abuela que ocupa una posición maternal en términos

Revista Zona Franca- Centro de estudios interdisciplinario sobre las mujeres (CEIM)- Maestría poder y sociedad desde la problemática de género (MG), Rosario, Argentina. ISSN, 2545-6504 http://zonafranca.unr.edu.ar/index.php/ZonaFrancal Número 28 (2020). 
estructurales (no necesariamente afectivos), puesto que oficia de "cuidadora" primaria. Por tanto, se opera un desvío de la descendencia, un desplazamiento genealógico, posiblemente involuntario en el primer caso, pero que en el segundo es resultado del ejercicio de la autoridad reguladora (y del ocultamiento de la verdad) que lleva a cabo.

Narrado por Laura, el relato se centra en la conversación secreta que deviene en un amor entre la protagonista y su sobrino-primo, Laurent-Macario, que vive recluido y oculto en el sótano de la casa custodiado por Encarnación (aunque recibe ciertas dosis de rayos solares a horas tempranas en que el resto de la casa duerme). A su madre, Eulalia, una curandera le quitó todo recuerdo de haber parido y le Figura 4.
Cartografia subjetiva
En $V A C D D$
Encarnación
Lauura restituyó la virginidad por orden de Encarnación. De modo que la existencia del niño debe permanecer en secreto. Sin embargo, Laura llega a presenciar la llegada del niño porque en ese momento ella tiene cinco años y está "en la frontera entre la fantasía y la idiotez", por lo cual la tía le dice (en lo que luego descubriría como una sesión de hipnotismo): "aquí no llegó ningún muñeco, tú lo has soñado, a veces les sucede eso a las niñas" (Somers 2011 15). A partir de un conocimiento intuitivo y de una rectificación empírica es que Laura inicia una comunicación a escondidas con el niño por un canal de ventilación, a través del cual baja y sube con un cordel, a modo de caña de pescar, unos carteles con mensajes y dibujos. La primera acción es otorgarle al niño-monstruo un nombre: dice llamarlo "Laurent" "porque yo soy Laura" (Somers 13). Cuando Laura revela su conocimiento de la existencia del niño, es enviada a Las Nubes, la hacienda familiar, como forma de castigo y se le asigna una maestra de piano. Esta estrategia de la tía parece tener la función de evitar un escándalo moral -durante un fin de una proyección del siglo XIX atípica, atravesado por inflexiones folletinescas-. Los personajes viven bajo una estricta autoridad

Revista Zona Franca- Centro de estudios interdisciplinario sobre las mujeres (CEIM)- Maestría poder y sociedad desde la problemática de género (MG), Rosario, Argentina. ISSN, 2545-6504 http://zonafranca.unr.edu.ar/index.php/ZonaFranca| Número 28 (2020). 
(Encarnación), aislados en menor o mayor grado y deben obediencia a ésta. La sexualidad está vetada y los espacios operan también con funciones diferenciadas: Las Nubes, la hacienda, es el sitio del "castigo" y del secreto, una suerte de "lazareto de cuarentena" (Somers 14) por la mayor posibilidad de reclusión e incomunicación de sus habitantes. Y luego está la vivienda "oficial", en la cual los secretos viven, pero aún más "enterrados". Sin embargo, a pesar de esa atmósfera oprimente y extrañada, hay (también de forma velada y secreta) una producción de afectos raros, incestuosos (el de Laura y el niño del sótano, Laurent-Macario; y también el de Encarnación hacia su nieto) y lésbicos (el de Laura y Hildegaard). Estos se constituyen en agenciamientos triangulares ajerárquicos que pugnan por disolver la rigidez de las distribuciones subjetivas a las que los personajes están sujetos.

Si la lógica de diferencias subjetivas que se instauran, a un nivel más general, es una jerarquía genealógica pero desviada, impuesta por un personaje que postula la norma (Encarnación, secundada por Refugio) y otros llamados a obedecer; entonces Encarnación viene a monopolizar, en términos de Foucault, el poder regulador de la sexualidad. Toma decisiones sobre otros cuerpos y placeres: impide a los habitantes de la casa deambular libremente por la casa por la mañana, manda a colocar barrotes en el cuarto de Laura en Las Nubes (para impedir todo contacto sexual furtivo), se encarga de buscar una maestra de piano virgen para no propagar sexualidad; entre otras prácticas. Sin embargo, algunos de los personajes subordinados son precisamente aquellos que subvierten las reglas sexuales y morales (Eulalia, Laura, Hildegaard). Lo que parece colarse entre las redes del poder es precisamente la potencia deseante, que se opone al discurso de poder de la matriarca. De modo que la familia Cienfuegos vive bajo un régimen de vigilancia no sólo de los cuerpos, los placeres, sino también de las identidades y las libertades individuales. Esto es, no sólo se cercenan las libertades individuales (el encierro y la condena a vivir en aislamiento de Macario-Laurent desde que es bebé), sino que opera toda una política de ocultamientos y manipulaciones corpo-identitarias: el despojo a Eulalia de la conciencia de su maternidad y la "restauración" de su

Revista Zona Franca- Centro de estudios interdisciplinario sobre las mujeres (CEIM)- Maestría poder y sociedad desde la problemática de género (MG), Rosario, Argentina. ISSN, 2545-6504 http://zonafranca.unr.edu.ar/index.php/ZonaFranca| Número 28 (2020). 
virginidad por una "comadrona mágica", al mismo tiempo que el engaño a LaurentMacario sobre sus verdaderos padres. De ahí que la palabra de la tía Encarnación sea la ley:

Las horas que indicaré son mías en exclusividad -dijo una vez y para siempre-, prohíbo desde mañana se ande a ciegas y tumbos por la casa moviendo cacharros, triturando café, batiendo manteca. Quienquiera que desobedezca no se pone contra mí, se junta con el diablo, el primero en rebelarse, y allá él... (Somers 18). (El subrayado es propio).

Dicha "orden" se escribe en un papel de embalar y se coloca sobre un mueble de la despensa. Laura no sabe leer en ese momento pero de ahí la rescata años después y parece "como si la voz hubiera quedado adherida a la letra para siempre". (Somers 18). De modo que se proscriben las conductas a partir de la ratificación en la escritura: la norma queda fijada materialmente y la letra sigue homologándose a la identidad de la voz emisora original. Pero además, la ley, al contraponerse a los oficios del "diablo", se ubica en un terreno de una moral religiosa; pero se revela más bien como una arbitrariedad amparada en el poder de la "matriarca" de dictar leyes. Dichas regulaciones tienen como objetivo resguardar la dimensión del secreto doméstico destinado a preservar cierta "honra" familiar cristiana en un ámbito público (aunque sólo intuido). De modo que, en términos concretos, las identidades familiares "aceptadas" pueden estar integradas, o al menos existir, dentro de la lógica familiar estándar -aunque éstas incluso son presas del despojo subjetivo a partir del engaño y las intervenciones medicinales o mentales más heterodoxas-. En segundo lugar, las identidades más rebeldes son asignadas a vivir en un régimen de mayor incomunicación en Las Nubes y las identidades "inaceptables" socialmente, pero no por ello desdeñadas: la de Laurent-Macario, recluidas a espacios otros invisibles y desconocidos para el resto de la familia y los empleados.

Sin embargo, pareciera que aquellos controles rigurosos de la sexualidad y de la corporalidad familiar, en lugar de engendrar castidad y obediencia, generan, por

Revista Zona Franca- Centro de estudios interdisciplinario sobre las mujeres (CEIM)- Maestría poder y sociedad desde la problemática de género (MG), Rosario, Argentina. ISSN, 2545-6504 http://zonafranca.unr.edu.ar/index.php/ZonaFranca| Número 28 (2020). 
el contrario, aquello que Foucault señaló a propósito de las técnicas de poder ejercidas sobre el sexo: la "diseminación e implantación de sexualidades polimorfas". (Foucault 2012 18). Se podrían pensar las relaciones intra-familiares y los afectos lésbicos que parecen como líneas de fuga en que el deseo cobran incluso vertientes insospechadas y más transgresoras que el amor heteronormativo y exogámico que se prohíben.

Por otra parte, otra contraposición que puede funcionar como línea de fuga es, sin dudas, el origen bi-religioso de Laura Kadisja Hassan y Cienfuegos: ella es hija de madre cristiana y padre árabe, fallecidos en un naufragio. En ocasiones invoca a Alá y hace referencia al Corán. Algo de ese índice de diferencia en Laura permite la subversión y desacato de la autoridad familiar. Presa de un "delirio destructivo" esto es, la introducción de lo entrópico y de la crisis en una familia en que se privilegia el secreto y falsedad- rompe tazas, vidrios de ventanas, libera a los pájaros de la jaula, luego de lo cual Encarnación la considera poseída por el demonio. Y luego, le revela su conocimiento de la existencia de Laurent-Macario, el secreto mejor guardado de la familia. También infringe las reglas frente a quien le está destinado como ladero, Juvencio, cuando desnuda su pecho frente a él mientras recogen moras y logra incomodarlo. Esto revela la relación de poder real que tienen. Del mismo modo, trata de atemorizarlo con la dramatización de la rivalidad entre musulmanes y cristianos mientras montan a caballo (como señala Somers en el texto de la contratapa, previo al conflicto moderno como tal, y muy posterior al de las cruzadas, por lo tanto, extemporáneo). De modo que la diferencia religiosa es utilizada como productora de incomodidad o temor (formas de "perversidad", según el diccionario de la protagonista). Por otra parte, están las subversiones sexuales y morales que produce Laura como tales: la relación amorosa platónica y lésbica con la Señorita Hildegaard y el vínculo sexual y afectivo con su sobrino-primo, Laurent. Otras formas más generales de desacato de la autoridad familiar son no respetar el duelo por su tía al ponerse un vestido rojo y,

Revista Zona Franca- Centro de estudios interdisciplinario sobre las mujeres (CEIM)- Maestría poder y sociedad desde la problemática de género (MG), Rosario, Argentina. ISSN, 2545-6504 http://zonafranca.unr.edu.ar/index.php/ZonaFrancal Número 28 (2020). 
como veremos, "profanar" las cartas del archivo familiar, pero más que eso, autodesignarse la nueva archivista del fondo documental de la familia.

De hecho, una de las fuentes de poder más efectivas que posee Encarnación son los caudales de información familiar que permanecen ocultos y velados para el resto: es la guardiana de las "verdades". De modo que lo que sostiene una ética del silencio (y de la ignorancia del resto de la familia) en la superficie es una proliferación escrita oculta: este aglomerado de información secreta conforma un archivo familiar de cartas ordenadas por fecha de llegada, ubicado en un cajón de Las Nubes descubierto por Laura. Allí se registran los secretos, ilegalidades y manejos de ocultamiento y tergiversación de identidades, y cuya archivista "de turno" es Refugio. Lo que allí se encuentra es el "horror" acumulado como en una "cueva de alimañas." (Somers 30). Laura se inaugura como una Refugio "más sistemática" cuyo objetivo es el de poner cada noticia en su contexto y encontrarle un sentido. De modo que, a partir de las series y las líneas temáticas que forman las cartas, Laura hace una tarea de hermeneuta para llenar los blancos y develar aspectos ocultos de las identidades, en especial, la suya propia: "no quise seguir leyendo dado lo oscuro que aquello me resultaba cuando lo que yo pretendía investigar era materiales transparentes que me llevaran a mí misma" (Somers 32) (El subrayado es propio). De modo que el rol de investigación que adopta Laura es, en principio, una búsqueda de la propia identidad, apuntalada también por otro nicho de información valiosa que está en los libros de bautismo que el padre Artemio pone a su disposición.

En relación a nuestro análisis posterior veremos por un lado identidades de desdoblamiento dual y tripartito (Laura-Laurent; Laura-Laurent-Sol y MelodieMozart-Hildegaard), que son aquellas que se afincan en vínculos deseantes y transgresivos: el incesto en los primeros dos casos y cierto afecto lesbiano platónico en el segundo caso. Estos agenciamientos, además, son propiciados a partir de la suplementariedad nominal, que es un eje vertebrador de la novela, y que implica, además, que los nuevos nombres adoptados sean también ciertos actos de

Revista Zona Franca- Centro de estudios interdisciplinario sobre las mujeres (CEIM)- Maestría poder y sociedad desde la problemática de género (MG), Rosario, Argentina. ISSN, 2545-6504 http://zonafranca.unr.edu.ar/index.php/ZonaFrancal Número 28 (2020). 
"colonización" del otro, que inauguran nuevas formas de relación, consensuadas y al margen del poder. Sólo para hacer una descripción preliminar, diremos que Laura nomina a su sobrino-primo, prisionero del sótano, como "Laurent"; que la maestra de piano, Hildegaard, le otorga el nombre "Melodie" a Laura y "Zauberei" al caballo que le otorgan (cuyo nombre primigenio es "Tormenta"). $Y$ estas formas de suplementariedad nominal se oponen a cierto estatismo nominal en otros personajes como Refugio o Encarnación.

\section{Consideraciones finales}

$\mathrm{Si}$ atendemos a los mapas subjetivos que se dibujan en cada novela, podemos resumir que en $L M D$ la vivencia de la protagonista es la de un nomadismo que se despoja de la moral sexual religiosa y de cualquier adscripción anterior, lo cual redunda en una subjetividad "desmarcada" y, al menos en un primer momento, neutra de atributos, hasta que se presenta su cuerpo incardinado (al menos en su posición de cuerpo de mujer, sustancializado); frente a las subjetividades aldeanas, "marcadas" y fijadas en una moral cristiana y patriarcal. Su objetivo es la fusión con subjetividades míticas, religiosas o literarias ya presentes en el discurso simbólico, y por tanto, se trata de una ipseidad total. Entraña en sí la alteridad, la cual se incorpora, como veremos, a partir de la suplementariedad nominal: Rebeca Linke se llama a sí misma Eva, Semíramis, Magdala, Judith, Gradiva y Friné. Por lo tanto, el mapa subjetivo dibuja una línea (el tránsito, la vivencia de presente y la mutabilidad de su protagonista) y sus inmediaciones, pero ésta no está exenta de contactos amorosos y conceptuales, de plegamientos dentro de esa línea con otras subjetividades, cuya relación excede en gran medida la mera oposición.

Por otra parte, en $V A C D D$, la oposición preliminar de subjetividades se da ya no en relación a una línea como en $L M D$, sino en un marco piramidal; entre la matriarca que detenta el poder regulador sobre cuerpos e identidades y los personajes bajo dicha estructura que encuentran formas de subversión y de potencia para producir fisuras dentro de ella. De modo que es posible debilitar o

Revista Zona Franca- Centro de estudios interdisciplinario sobre las mujeres (CEIM)- Maestría poder y sociedad desde la problemática de género (MG), Rosario, Argentina. ISSN, 2545-6504 http://zonafranca.unr.edu.ar/index.php/ZonaFranca| Número 28 (2020).

Página 432 
torcer esa estructura rígida u opositiva, tanto en el caso de $L M D$ como en el de $V A C C D$, a partir de agenciamientos amorosos, que en éste último caso forman formas triangulares ajerárquicas alternativas a la pirámide de poder dentro de la cual los personajes habitan. Por otra parte, VACCD presenta formas de rebelión subjetiva que ya no van a estar habilitadas por factores simbólico-culturales. Mientras que en $\angle M D$ la protagonista se desubjetivaba e iniciaba su trayecto lineal, a partir de su auto-investimento de los nombres y cualidades de figuras del acervo cultural, en $V A C C D$ ya no es el universo cultural el que habilita las mutaciones subjetivas y los encuentros deseantes, sino, precisamente, formas de invención de sí y del otro que no están mediadas por otros discursos y surgen de la dimensión individual de los personajes. En cierto sentido, éstos se emancipan de la necesidad de un fundamento simbólico para devenir otros.

\section{Bibliografía}

SOMERS, Armonía (1950 [2009]). La mujer desnuda. Buenos Aires: El cuenco de plata.

---. (1986 [2011]). Viaje al corazón del día: elegía por un secreto amor. Buenos Aires: El cuenco de plata.

ARFUCH, Leonor (2005). (Comp.) Identidades, sujetos, subjetividades. Buenos Aires: Prometeo.

BRAIDOTTI, Rosi (2004). Feminismo, diferencia sexual y subjetividad nómade. Barcelona: Gedisa.

BLANCHOT, Maurice (2001). "Lo extraño y lo extranjero", en revista Archipiélago, No. 49.

---. (1993). El diálogo inconcluso. Caracas: Monte Ávila.

BUTLER, Judith (2007). El género en disputa: el feminismo y la subversión de la identidad. Barcelona: Paidós.

---. (2006). Deshacer el género. Barcelona: Paidós.

CALAFELL SALA, Núria (2010). Armonía Somers: por una ética de lo excéntrico. Vigo: Academia del Hispanismo.

Revista Zona Franca- Centro de estudios interdisciplinario sobre las mujeres (CEIM)- Maestría poder y sociedad desde la problemática de género (MG), Rosario, Argentina. ISSN, 2545-6504 http://zonafranca.unr.edu.ar/index.php/ZonaFrancal Número 28 (2020). 
---. (2011). "Todas en ella: Armonía Somers y la lectoescritura como construcción identitaria", en revista Nomadías, (13), julio, 31-45.

CATANZARO, Gisela (2005). "Materia e identidad: el objeto perdido". En L. Arfuch (Comp.), Identidades, sujetos, subjetividades. Buenos Aires: Prometeo.

DELEUZE, Gilles y GUATTARI, Félix (2002). Mil mesetas: capitalismo y esquizofrenia. Valencia: Pre-textos.

FOUCAULT, Michel (2002). La arqueología del saber. Buenos Aires: Siglo veintiuno.

--- (2012). Historia de la sexualidad: 1. la voluntad del saber. Buenos Aires: Siglo veintiuno.

FRANCO, Graciela (2005). "La belleza y el poder: Armonía Somers y la crítica hegemónica". Encuentro de Literatura Uruguaya de Mujeres, \& Guariglia, Z. M. (Comps.) La palabra entre nosotras. Montevideo: Ediciones de la Banda Oriental.

GUATTARI, Félix y ROLNIK, Suely (2006). Micropolítica: cartografías del deseo. Traficantes de sueños.

HALL, Stuart (2003). “¿Quién necesita “identidad”?”. S. Hall y P. du Gay (Eds.), Cuestiones de identidad cultural. Buenos Aires: Amorrortu.

LÁZARO, Luis Alberto (1996). "El concepto de modernismo en la literatura inglesa", en J.M. Losada, A. Rodríguez López-Vázquez y K. Reichenberger, (Eds.). De Baudelaire a Lorca: acercamiento a la modernidad literaria. Kassel: Reichenberger.

POTENTE, Candela (2011). "Lo neutro en Blanchot, sustantivo sin sustancia". Simposio o conferencia llevado a cabo en I Jornadas de Estudiantes del Departamento de Filosofía, Buenos Aires, Universidad de Buenos Aires, Facultad de Filosofía y Letras.

RICOEUR, Paul (2006). Sí mismo como otro. México, D.F.: Siglo veintiuno.

RODRÍGUEZ MONEGAL, Emir (1953). "Onirismo, sexo y asco". En semanario Marcha, (679).

RODRÍGUEZ VILLAMIL, Ana María (1990). Elementos fantásticos en la narrativa de Armonía Somers. Montevideo: Ediciones de La Banda Oriental.

Revista Zona Franca- Centro de estudios interdisciplinario sobre las mujeres (CEIM)- Maestría poder y sociedad desde la problemática de género (MG), Rosario, Argentina. ISSN, 2545-6504 http://zonafranca.unr.edu.ar/index.php/ZonaFranca| Número 28 (2020). 
Revista Zona Franca- Centro de estudios interdisciplinario sobre las mujeres (CEIM)- Maestría poder y sociedad desde la problemática de género (MG), Rosario, Argentina. ISSN, 2545-6504 http://zonafranca.unr.edu.ar/index.php/ZonaFrancal Número 28 (2020). 